\title{
Evaluation of Locally Available Substrates for Sporocorps Production of Pink Pleurotus [Pleurotus djamor (Rumph.ex.Fr.) boedijn] Mushroom
}

\author{
Shazia Paswal ${ }^{\text {* }}$, Najeeb Mughal ${ }^{1}$, Varsha Bharti ${ }^{1}$, Seethiya Mahajan ${ }^{2}$ and Misba Majeed ${ }^{2}$ \\ ${ }^{1}$ Division of plant pathology, Sher-e- Kashmir University of Agricultural Science and \\ Technology of Jammu Chatha - 180009, India \\ ${ }^{2}$ Division of plant pathology, Sher-e- Kashmir University of Agricultural Science and \\ Technology of Srinagar - 190025, India \\ *Corresponding author
}

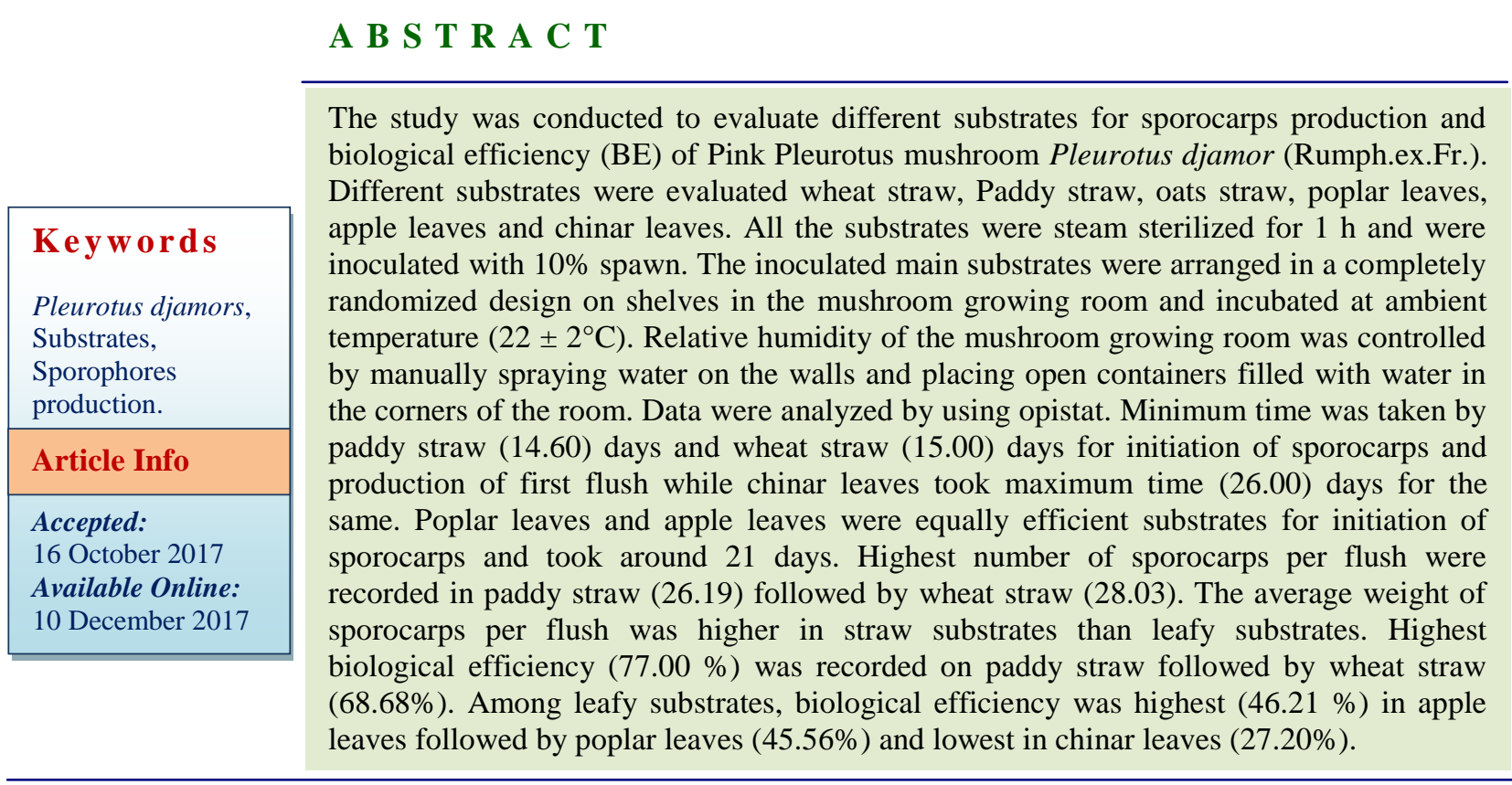

\section{Introduction}

Cultivation and production of edible mushrooms are on the increase, particularly in Europe, America and Asia. Their increased nutritional importance is due to the nutritive value of high grade mushrooms, which almost equals that of milk. Edible mushrooms have long been considered to have medicinal value and to be devoid of undesirable effects. Cultivation and production of edible mushrooms are on the increase, particularly in Europe, America and Asia. Their increased nutritional importance is due to the nutritive value of high grade mushrooms, which almost equals that of milk. Mushroom are now getting significant importance due to their nutritional and medicinal value and today their cultivation is being done in more than 100 countries. At present world mushroom 
production is around 7 million tonnes and is ever increasing. Globally China is the leading producer as well as consumer of mushrooms. India has got 16th rank as per 2013 reports. Oyster mushroom is the fourth important cultivated mushroom in the world and contributes about $2.7 \%$ of total production of fresh mushroom.

As among the different cultivated edible fungi, species of Pleurotus are the easiest and cheapest to grow and are better in consumer aspects than the generally grown button mushroom. Pleurotus species has been regarded as an edible mushroom the past many years. Pleurotus florida posses antioxidant, immunostimulant, antitumour and anti-inflammatory activities. The natural advantage of mushroom cultivation in India is due to the presence of seasonal variation, abundance and availability of variety of agro wastes at low prices. Species of Pleurotus may be called as oyster, abalone or tree mushroom. It belongs to the Class Basidiomycetes.

The genus has more than 50 species. Some of the members are Pleurotus eryngii, Pleurotus sajor-caju. Pleurotus florida, Pleurotus flabellatus, Pleurotus ostreatus, Pleurotus eous etc. Pleurotus eous is selected for the present study, which is commonly known as pink oyster mushroom and the species can be easily identified by the pinkish tints of the pileus and the small narrow spores.

\section{Materials and Methods}

The present studies were carried out in Mushroom Research \& Training Centre, Division of Plant Pathology, Sher-e-Kashmir University of Agricultural Sciences \& Technology of Kashmir, Shalimar campus, Srinagar during 2013-2014.All the substrate were collected from Shalimar Campus SKUAST-K district srinagar.

\section{Procurement and maintenance of culture}

The pure culture of Pleurotus djamor (Rumph. ex. Fr.) Boedijn was procured from Directorate of Mushroom Research, Chambaghat, Solan. Pure cultures were transferred into sterile potato dextrose agar (PDA) slants. The slant cultures were stored at ambient temperature $\left(29 \pm 2{ }^{\circ} \mathrm{C}\right)$ for 7 days; after which the slants were kept in a refrigerator at $4 \pm 2{ }^{\circ} \mathrm{C}$.

\section{Spawn preparation}

Apparently healthy, unbroken wheat grains were used for 'Master Spawn' preparation and the procedure given by Patil (2012) was followed. Wheat grains were washed 2-3 times with tap water and boiled in plain water for 10-15 minutes till the grains were soft. These grains were then dried under shade by spreading them on wire mesh followed by mixing with calcium carbonate and calcium sulphate in 1:4 ratio after cooling of grains. The grain mixture was filled in empty, well cleaned narrow mouthed bottles upto $3 / 4^{\text {th }}$ of their capacity and plugged with non-absorbent cotton and sterilized in autoclave at $1.05 \mathrm{~kg}$ $\mathrm{cm}^{-2}$ pressure and $121^{\circ} \mathrm{C}$ temperature for one and half hour. The sterilized bottles were taken out of the autoclave and allowed to cool at room temperature and inoculated with pure culture of 'Pink Pleurotus' (Pleurotus djamor), procured from DMR, Chambaghat, Solan, under aseptic conditions of 'Laminar Air Flow Cabinet'. The inoculated bottles were kept for incubation in B.O.D incubator at $25 \pm 2{ }^{\circ} \mathrm{C}$ till the colonisation of the grains was complete. The spawn bottles free from any contamination were used as a master culture.

\section{Substrate preparation}

The procedure described by Patil (2012) was followed for substrate preparation. Each 
substrate was chopped into 2 to $3 \mathrm{~cm}$ pieces and separately soaked in water overnight. The substrates were then separately dipped in hot water for 30 minutes for sterilization. The substrates were taken out of hot water and squeezed lightly by hands to remove excess of water. Two kilograms (on dry weight basis) of each substrate was then filled in polythene bags $(35 \times 45 \mathrm{~cm})$ and pressed gently. Filling and spawning of substrates was done simultaneously. Filling of substrates in the polythene bags was done in layers. Multi layered spawning technique was adopted for spawning of substrates and 2 per cent spawn was used. The corners and lower centre at the base of polythene bags were cut with scissors and holes were made to avoid any accumulation of water in the bags. Each treatment was replicated ten times and the bags were arranged in completely randomized design. These bags were then incubated at 25 $\pm 2^{\circ} \mathrm{C}$ temperature inside the cropping room.

\section{Calculation of biological efficiency}

Biological efficiency of each substrate was calculated using the formula

Fresh weight of mushroom Biological efficiency $(\%)=$---------- X 100

Dry weight of substrate

\section{Results and Discussion}

All the substrates supported for the sporocarps of 'Pink Pleurotus'. However time required for sporocarps initiation differed with different substrates. The time taken for Sporocarps initiation ranged from 13.60 to 24.00 days while time taken for first flush ranged from 18.70 to 27.30. Minimum time was taken by paddy straw (14.60) days and wheat straw (15.00) days for initiation of sporocarps and production of first flush while chinar leaves took maximum time(26.00) for the same. Poplar leaves, oats straw and apple leaves were equally efficient substrates for initiation of sporocarps and took around 21 days. The slow sporocarp initiation and production of first flush in chinar leaves may be attributed to its texture and composition. Furthermore, since the mushrooms are saprophytic in nature, the slower rate of decomposition of chinar leaves may be one of the possible reasons responsible for slow growth and frutification of 'Pink Pleurotus'. The results of present investigation are in agreement with the findings of Chauhan et al., (2012) who reported pin head formation on wheat straw was completed in 12.75 and 14.25 days, respectively while Sharma (2005) recorded 15.80 and 16.50 days for sporocarp initiation of 'Pink Pleurotus' on paddy straw and wheat straw, respectively. The results of other scientists who findings are in conformity with present finding are Patra and Pani (1995), Shah et al., (2004), Rajak et al., (2011) and Sidhant et al., (2013). The highest number of sporocarps per flush were recorded in paddy straw (26.19) followed by wheat straw (28.03) (Fig. 1) whereas among leafy substrates, highest number of sporocarps were recorded in apple (22.73) and poplar leaves (19.32) while chinar leaves recorded lowest number of sporocarps (13.11). The number of sporocarps decreased with every flush except in chinar leaves where number of sporocarps in second flush were higher (24.00) than first flush (22.00).

The average weight of sporocarps per flush was higher in straw substrates than leafy substrates (Fig. 2). Paddy straw produced sporocarp with highest average weight $(13.47 \mathrm{~g})$ while lowest average weight of sporocarp $(6.87 \mathrm{~g})$ was recorded in chinar leaves. The production of oyster mushroom in paddy straw was very high, because the paddy straw contain all the essential micronutrients for the development of mushroom such as minerals, vitamins, amino acids etc., (Govindaraju, 2013). 
Table.1 Effect of different substrates on the biological efficiency and substrate to yield ratio of 'Pink Pleurotus' (P. djamor)

\begin{tabular}{lcc}
\hline Substrate & Biological efficiency (\%) & Substrate to yield ratio (S:Y) \\
\hline Paddy straw & 77.00 & $1: 0.77$ \\
Oats straw & 51.95 & $1: 0.51$ \\
Apple leaves & 47.15 & $1: 0.47$ \\
Chinar leaves & 27.20 & $1: 0.27$ \\
Poplar leaves & 45.59 & $1: 0.44$ \\
Wheat straw (check) & 67.68 & $1: 0.67$ \\
$\quad \mathbf{S . E}(\mathbf{d})$ & 0.002 & \\
\hline C.D $(\mathbf{p} \leq \mathbf{0 . 0 5})$ & 0.005 & \\
\hline
\end{tabular}

Fig.1 Initiation of sporocarps of Pink Pleurotus on different substrates

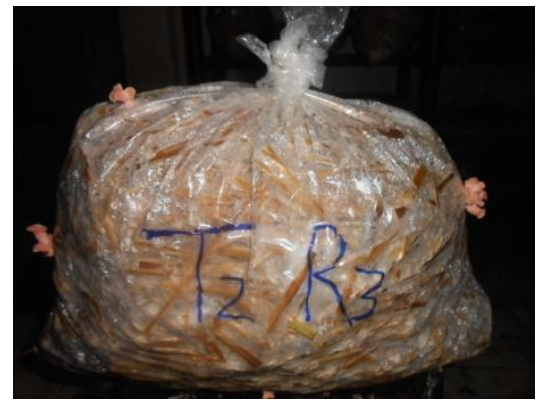

Sporocarps initiation on paddy straw

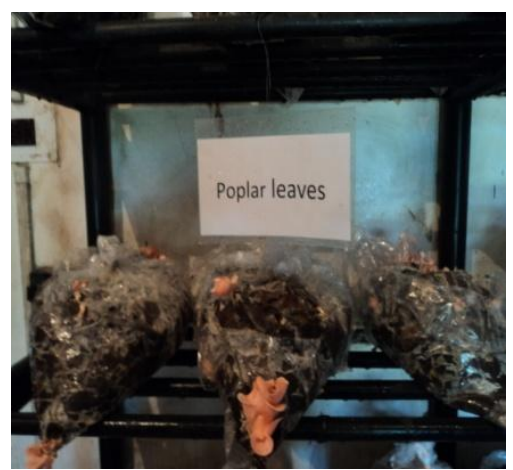

Sporocarp initation on poplar leaves

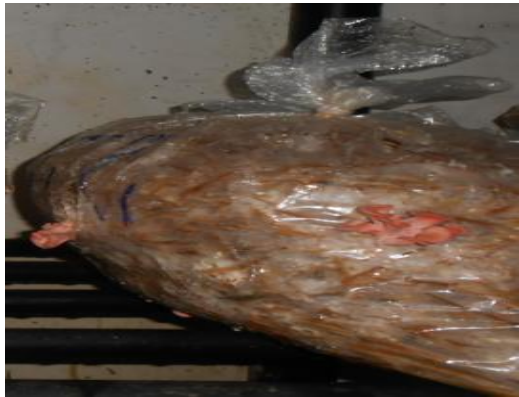

Sporocarps initiation on wheat straw

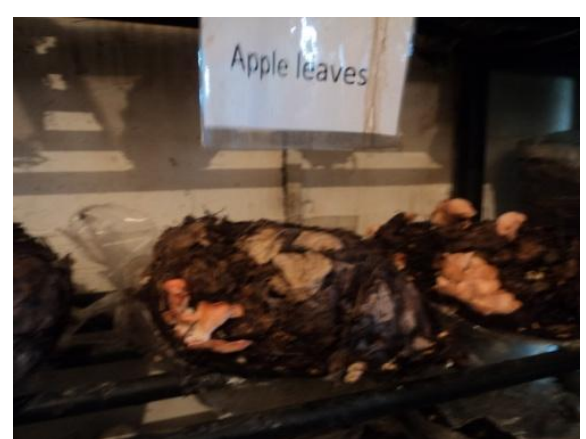

sporocarp initiation on apple leaves

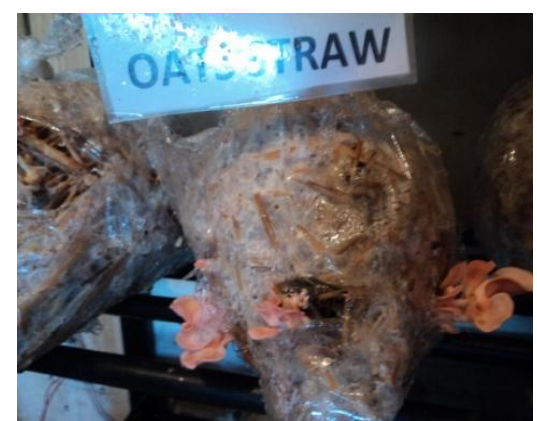

Sporocarp initiation on oats straw

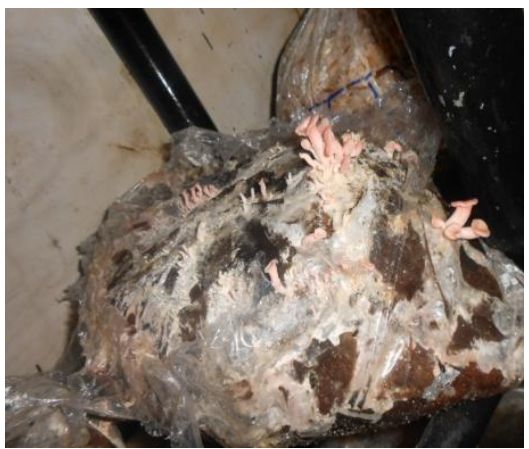

sporocarp initiation on chinar leaves 
Fig.2 Mature sporocarps of Pink Pleurotus on different substrates (A) paddy straw, (B) wheat straw, (C) oats straw (D) Apple leaves, (E) Chinar leaves, (F) poplar leaves
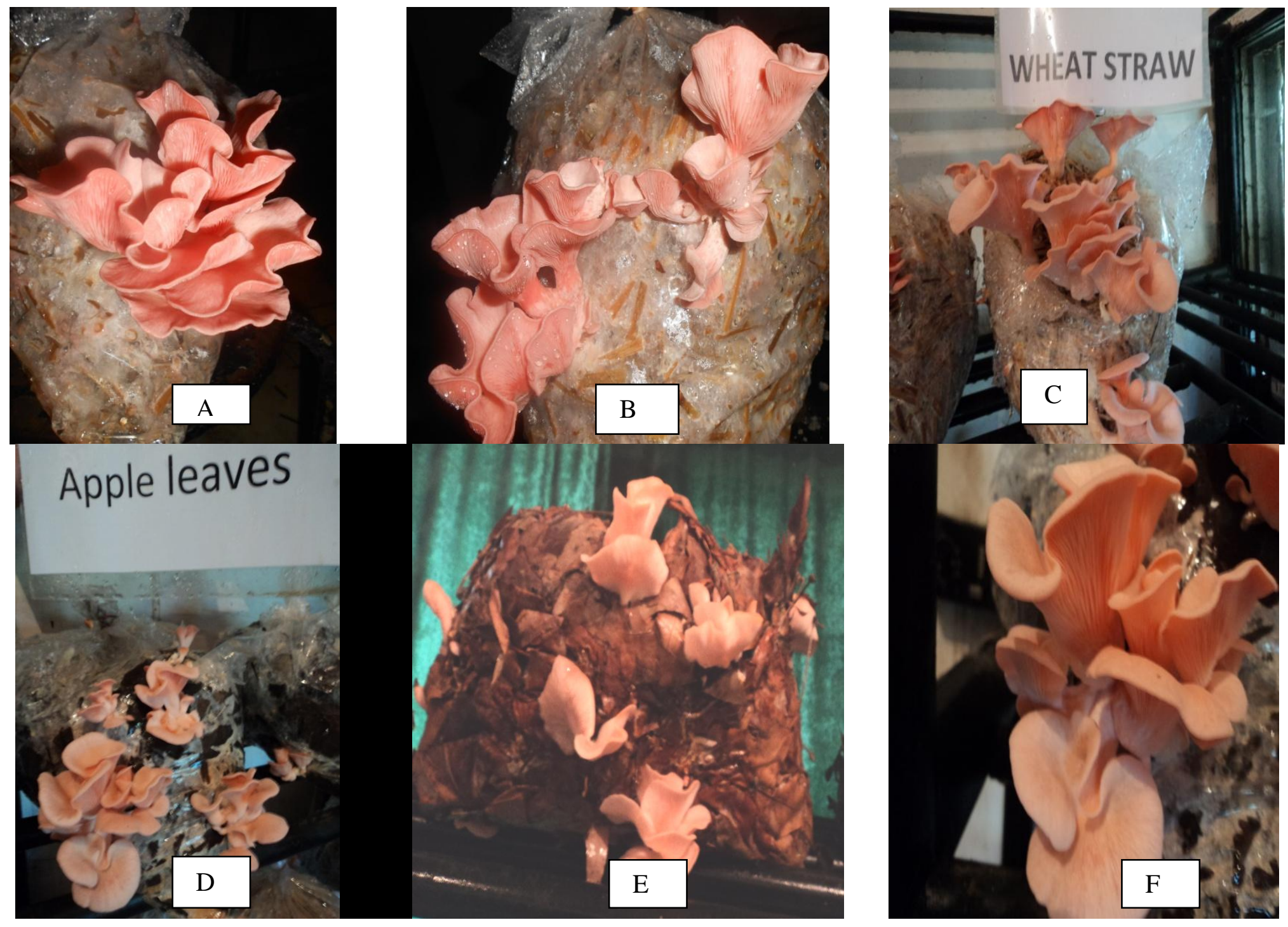
Graph.1 Effect of different substrates on numbers

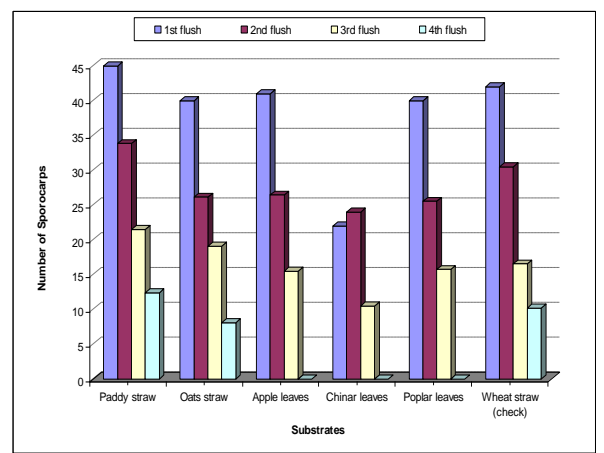

Sporocarps of 'pink Pleurotus'

Although four sporocarp flushes were recorded in straw substrates, the crop duration was also found less in straw substrates than leafy substrates because the early initiation of sporocarp formation and less time interval between flushes. The present results are in conformity with those of Pala et al., (2012) who recorded four flushes of mushroom on paddy straw and wheat straw and recorded highest yield of Pleurotus sp. from paddy straw. Similar findings were also recorded by Dwevidi and Singh (1994), Zhang et al., (2002), Rajak et al., (2011), Sofi et al., (2014).

Biological efficiency of 'Pink Pleurotus' to utilize the substrate for producing yield varied with different substrates. Highest biological efficiency $(77.00 \%)$ was recorded on paddy straw followed by wheat straw $(68.68 \%)$ (Table 1). Among leafy substrates, biological efficiency was highest $(46.21 \%)$ in apple leaves followed by poplar leaves (45.56\%) and lowest in chinar leaves $(27.20 \%)$. The substrate to yield ratio was superior in case of paddy straw (1: 0.77) followed by wheat straw (1: 0.68) and oats straw (1:0.53). Among leafy substrates, apple leaves resulted in highest substrate to yield ratio (1:0.46) followed by poplar leaves (1:0.45) and chinar leaves $(1: 0.27)$. The substrate to yield ratio indicate the potential of substrate to produce

\section{Graph.2 Effect of different substrates on weight}

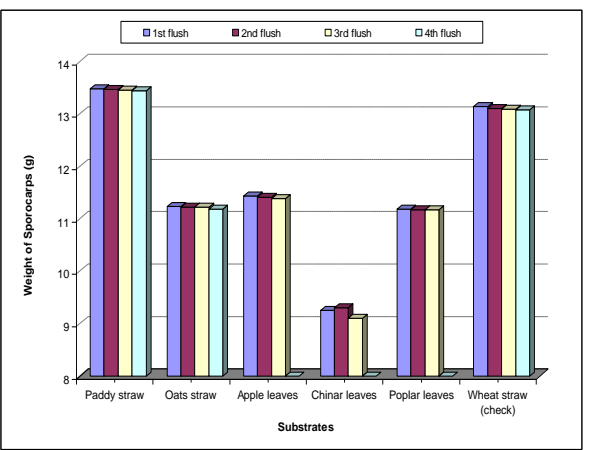

Sporocarps of 'Pink Pleurotus'

yield and confirm the suitability of substrate. The results of present investigation on biological efficiency are in conformity with the investigations of various researchers. Chang et al., (1981) reported that the P. sajorcaju, grown on paddy straw and cotton waste, gave biological efficiencies of 77.41 and $79.81 \%$, respectively while Sidhant et al., (2013) recorded biological efficiency of 'Pink Pleurotus' (P. eous) as high as 67.20 per cent in wheat straw. Khan et al., (2013) reported 85.00 and 77.00 per cent biological efficiency of Pleurotus spp. in paddy and wheat straw while Sofi et al., (2014) recorded 63.00 per cent biological efficiency of $P$. ostreatus in wheat straw.

The main objective of the present study was to find out the suitability of locally available substances as substrates for the sporocarp production of Pleurotus djamor. Six different such substances were selected and they were paddy straw, wheat straw, oats straw, poplar leaves, apple leaves, and chinar leaves. For the sterilization of substrates steam sterilization was adopted, no chemicals were used. The major observations were listed as number of sporocarps produced, total weight of sporocarps, and biological efficiency. In general, the straw substrates viz., paddy straw, wheat straw and oat straw were found superior than leafy substrates (apple, chinar 
and poplar leaves). Highest number of sporocarps per flush were recorded in paddy straw (26.19) followed by wheat straw (28.03) (Graph 1). The average weight of sporocarps per flush was higher in straw substrates than leafy substrates. Highest biological efficiency $(77.00 \%)$ was recorded on paddy straw followed by wheat straw (68.68\%) (Graph 2). Among leafy substrates, biological efficiency was highest $(46.21 \%)$ in apple leaves followed by poplar leaves $(45.56 \%)$ and lowest in chinar leaves $(27.20 \%)$.

\section{References}

Chang S T 1981. Mushroom and mushroom science. Mushroom Journal Tropics 3 : 2-4.

Chauhan P, Dharmesh G, Suman B C and Manju S 2012. Growth, development and yield of pink oyster mushroom, Pleurotus djamor (Rumph.) Boedijn as affected by different spawn rates. Department of Plant Pathology, Dr. Y.S. Parmar University of Horticulture and Forestry, Nauni, Solan (HP).

Dwevidi, R.P. and Singh, R.P. 1994. Studies on different Pleurotus spp. for their yield performance in north-west tarai of utter Pradesh (Abst.). National Symposium on Mushroom NRCM, Solan. April 8-10, pp. 28.

Govindraju S 2013. Effect of different agrowastes on mass production of edible mushroom Pleurotus ostreatus. Research Paper on Biology 3(6) : 22495555.

Jan-Shaheen K 2001. Quality spawn production and yield optimization of Pleurotus ostreatus (Jacq.ex.Fr.) Kummer, under Kashmir conditions. M.Sc. Thesis submitted to Sher-eKashmir University of Agricultural Sciences and Technology of Kashmir, Kashmir, pp. 87.
Jose N, Ajith TA, Janardhanan KK. 2004. Methanol extract of the oyster mushroom, Pleurotus florida, inhibits inflammation and platelet aggregation. Phytother Research. 18:43-6.

Khan M W, Muhammad A A, Nasir A K, Muhammad A K, Abdul R and Nazir J 2013. Effect of different levels of lime and ph on mycelial growth and production efficiency of oyster mushroom (Pleurotus spp.). Pakistan Journal Botany 45(1): 297-302.

Pala S A, Abdul H W and Riyaz A M 2012. Yield performance of Pleurotus sajorcaju on different agro-based wastes. Annals of Biological Research 3(4) : 1938-1941.

Patil S S 2012. Cultivation of Pleurotus sajorcaju on different agro wastes. Science Research Reporter 2(3) : 225-228.

Patra A K and Pani B K 1995. Yield response of different species of oyster mushroom (Pleurotus) to paddy straw. Current Agriculture Research 8: 11-14.

Rajak S, Mahapatra S C and Basu M 2011. Yield, fruit body diameter and cropping duration of oyster mushroom (Pleurotus sajor caju) grown on different grasses and paddy straw as substrates. Science Domain International $1: 10-17$

Roy SK, Das D, Mondal S, Maiti D, Bhunia B, Maiti TK. 2009. Structural studies of an immune enhancing water soluble glucan isolated from hot water extract of an edible mushroom, Pleurotus florida, cultivar Assam Florida. Carbohydrates Research. ;344:2596601.

Sanchita S 2008. Training report on mushroom cultivation. ICAR Research complex Eastern region Patna Shah Z A, Ashraf M and Ishtiaq C 2004. Comparative study on cultivation and yield performance of Oyster mushroom (Pleurotus ostreatus) on different substrates (wheat straw, leaves, saw 
dust). Pakistan Journal of Nutrition 3(3) : 158-160.

Shah, Z.A., Ashraf, M. and Ishtiaq, C. 2004. Comparative study on cultivation and yield performance of Oyster mushroom (Pleurotus ostreatus) on different substrates (wheat straw, leaves, saw dust). Pakistan Journal of Nutrition 3(3) : 158-160

Sharma B B 2005. Influence of environmental conditions on spawn run, pin head formation and biological efficiency of Pleurotus djamor. Indian Phytopathology 58(1): 63-66.

Siddhant Swapanil Y, Aquil A and Singh C S 2013. Effect of wheat straw components on the yield of Pleurotus eous. International Journal of Current Microbiology and Applied Sciences
2(8): 221-225.

Siddhant, Swapnil, Y. and Singh, C.S. 2013. Spawn and Spawning Strategies for the Cultivation of Pleurotus eous (Berkeley) Saccardo. International Journal of Pharmaceutical and chemical sciences.

Sofi B, Mushtaq A and Moinuddin K 2014. Effect of different grains and alternate substrates on oyster mushroom (Pleurotus oystreatus) production. African Journal of Microbilogy Research 8(14): 1474-1479.

Zhang, R., Li, X. and Fadel, J.G. 2002. Oyster mushroom cultivation with rice and wheat straw. Bioresearch Technology 82: $277-284$.

\section{How to cite this article:}

Shazia Paswal, Najeeb Mughal, Varsha Bharti, Seethiya Mahajan and Misba Majeed. 2017. Evaluation of Locally Available Substrates for Sporocorps Production of Pink Pleurotus [Pleurotus djamor (Rumph.ex.Fr.) boedijn] Mushroom. Int.J.Curr.Microbiol.App.Sci. 6(12): 1677-1684. doi: https://doi.org/10.20546/ijcmas.2017.612.189 